\title{
Direct Determination of Molecular Weight and Its Distribution by the Absolute Calibration Method Using the On-Line GPC/NMR
}

\author{
Koichi Hatada, ${ }^{\dagger}$ Koichi Ute, Masaharu Kashiyama, \\ and Mamoru IMANARI*1 \\ Department of Chemistry, Faculty of Engineering Science, \\ Osaka University, Toyonaka, Osaka 560, Japan \\ *1 JEOL Ltd., Akishima, Tokyo 196, Japan
}

(Received September 18, 1989)

\begin{abstract}
The gel permeation chromatography of isotactic PMMAs containing exactly one $t$-butyl group per chain at the chain end was performed on a chromatograph linked to a $500 \mathrm{MHz}$ ${ }^{1} \mathrm{H}$ NMR spectrometer. The $\bar{M}_{n}$ of the solute PMMA can be directly determined from the intensities of ${ }^{1} \mathrm{H}$ NMR signals due to $t$-butyl and methoxy groups with a time resolution of $24 \mathrm{~s}$. Tapered structures at the ends of the NMR flow-cell are effective for preventing broadening of the elution band. $\log \left(\bar{M}_{n}\right) v s$. elution time plots for the three PMMA samples $\left(\bar{M}_{n}=3160,5260\right.$, 12600) fall on a single straight line. The results demonstrate the feasibility of the on-line GPC/NMR as an absolute calibration method for GPC.

KEY WORDS Poly(methyl methacrylate) / GPC / NMR / On-Line GPCNMR / Molecular Weight Distribution / Calibration Curve /
\end{abstract}

Determination of molecular weight by GPC requires a calibration curve, for which a set of standard polystyrenes with narrow molecular weight distribution are usually used. The only exception at present is dual detection of a GPC chromatogram by a combination of $\mathrm{UV}$ or refractive index (RI) method with low angle light-scattering, in which the weight-average molecular weight $\left(\bar{M}_{w}\right)$ of a given polymer can be determined without a calibration curve. ${ }^{1}$

The usefulness of a polymer having a known amount of chromophore groups per chain for absolute molecular weight calibration in GPC has been noted recently. ${ }^{2}$ This technique was applied to the determination of instrumental broadening in GPC using the polystyrene polymerized with bis(3-phenylazo)benzoyl peroxide and the chromatograph equipped with a variable wavelength UV detector which is sensitive to both the chromophore and polymer. ${ }^{3}$

NMR spectrometer is sensitive to mass concentration and also to the number-average molecular weight $\left(\bar{M}_{n}\right)$ of the solute polymer if the polymer molecule contains a known amount of end groups per chain. Recent progress in NMR spectrometer on the sensitivity and resolution has made it possible to use the spectrometer as a real-time detector of GPC. We reported that the on-line GPC/NMR method using a $500 \mathrm{MHz}{ }^{1} \mathrm{H}$ NMR spectrometer is useful for analyzing the molecular weight and structure of homopolymers, copolymers and oligomers. ${ }^{4-7}$ In this work, the potential feasibility of the on-line GPC/NMR technique was realized in the preparation of an accurate calibration curve for highly isotactic PMMA

\footnotetext{
† To whom correspondence should be addressed.
} 
with one $t-\mathrm{C}_{4} \mathrm{H}_{9}$ - group at the left (initiating) end of the polymer chain.

\section{EXPERIMENTAL}

The isotactic PMMAs used in this work were prepared by living polymerization with $t$ $\mathrm{C}_{4} \mathrm{H}_{9} \mathrm{MgBr}$ in toluene at $-78^{\circ} \mathrm{C}^{8}$ The PMMA molecule contains one $t-\mathrm{C}_{4} \mathrm{H}_{9}$ - group at the left end of the chain and the $\bar{M}_{n}$ s can be determined by intensity measurements of ${ }^{1} \mathrm{H}$ NMR signals due to $t-\mathrm{C}_{4} \mathrm{H}_{9}$ - and $\mathrm{CH}_{3} \mathrm{O}$ groups. The results of characterization of the PMMA samples are given in Table I.

The on-line GPC/NMR system consisted of a JEOL JNM-GX500 spectrometer and a JASCO TRI ROTAR-V chromatograph equipped with a Shodex GPC column KF$802.5(30 \mathrm{~cm} \times 0.8 \mathrm{~cm}$, maximum porosity $=$ $2 \times 10^{4}$ ). A $5 \mathrm{~mm}$ glass tubing (inner diameter $=2 \mathrm{~mm}$ ) having a tapered structure at both ends was used for the NMR observation flow cell (Figure 1). Detection volume is about $0.060 \mathrm{ml}$. A similar type of NMR flow cell has been used in the on-line HPLC/NMR experiments. $^{9,10}$ Further details of the system are described in previous papers. ${ }^{4-7}$ Chloroform$d$ containing $0.5 \%$ ethanol- $d_{6}$ was used as an eluent and the flow rate was $0.2 \mathrm{ml} \mathrm{min}^{-1}$. The ${ }^{2} \mathrm{D}$ NMR signal of the eluent was satisfactorily intense for internal lock and shimming of the magnetic field. Background signals due to the small amount of impurities in the eluent, except for the signal of $\mathrm{H}_{2} \mathrm{O}$, could be eliminated by subtracting the base line absorbance. The spinlattice relaxation times $\left(T_{1} \mathrm{~s}\right)$ for the $\mathrm{CH}_{3} \mathrm{O}$-and

Table I. Characterization of PMMA samples

\begin{tabular}{|c|c|c|c|c|c|}
\hline \multirow{2}{*}{$\bar{M}_{n}^{\mathrm{a}}$} & \multicolumn{2}{|c|}{$\bar{M}_{w} / \bar{M}_{n}$} & \multicolumn{3}{|c|}{ Tacticity $/ \%$} \\
\hline & GPC/RI & GPC/NMR & $m m$ & $m r$ & $r r$ \\
\hline 3160 & 1.19 & 1.15 & 95.3 & 4.3 & 0.4 \\
\hline 5260 & 1.13 & 1.13 & 96.9 & 3.0 & 0.1 \\
\hline 12600 & 1.18 & 1.13 & 97.7 & 2.1 & 0.2 \\
\hline
\end{tabular}

${ }^{\text {a }}$ Determined by ${ }^{1} \mathrm{H}$ NMR.
$t-\mathrm{C}_{4} \mathrm{H}_{9}$ - resonances were found to be $1.02 \mathrm{~s}$ and $0.51 \mathrm{~s}$, respectively. Thus, $45^{\circ}$ observation pulse $(2.9 \mu \mathrm{s})$ and the repetition time of $3.0 \mathrm{~s}$ were used for correct measurement of intensity (magnetization recovers theoretically $98.5 \%$ and $99.9 \%$ of equilibrium state for $\mathrm{CH}_{3} \mathrm{O}$ and $t-\mathrm{C}_{4} \mathrm{H}_{9}$ - resonances, respectively). The amounts of samples loaded were $0.4 \mathrm{mg}$, $0.5 \mathrm{mg}$, and $0.9 \mathrm{mg}$ for the PMMAs of $\bar{M}_{n}=$ 12600, 5260, and 3160, respectively. The ${ }^{1} \mathrm{H}$ NMR data, each consisting of 8192 data points covering $4500 \mathrm{~Hz}$, were collected over the entire chromatographic peak and stored

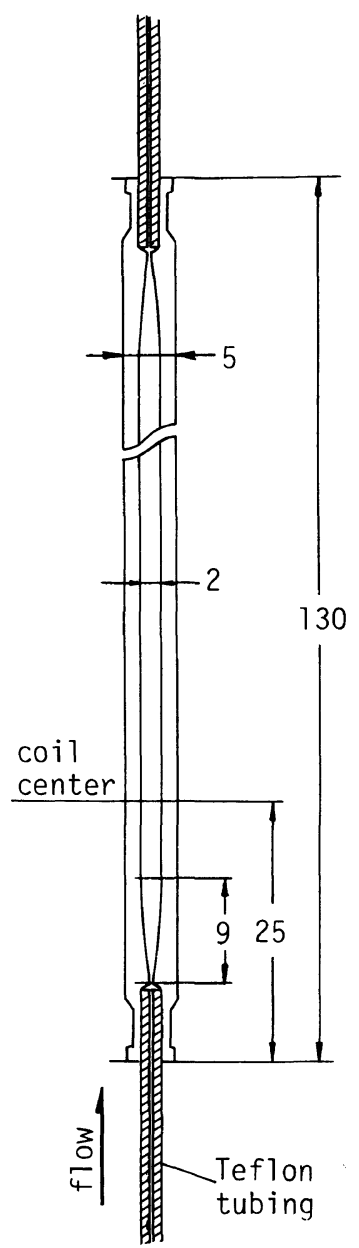

Figure 1. Schematic diagram of the $5 \mathrm{~mm}$ glass tubing used for the NMR observation flow cell. The figures indicate length in $\mathrm{mm}$. 
as 8 coadded scans every $24 \mathrm{~s}$. A line broadening factor of $0.55 \mathrm{~Hz}$ was applied.

\section{RESULTS AND DISCUSSION}

Figure 2 shows the GPC/NMR data of the isotactic PMMA with $\bar{M}_{n}$ of 12600 . The cross section at $3.60 \mathrm{ppm}$, where the methoxy protons resonate, gives the ${ }^{1} \mathrm{H}$ NMR-detected GPC chromatogram. The ${ }^{1} \mathrm{H}$ NMR-detected
GPC chromatograms of the three PMMA samples are shown in Figure 3, together with those recorded with an RI detector. The peak shapes of both the ${ }^{1} \mathrm{H}$ NMR-detected and RIdetected chromatograms are very similar to each other, and the difference in elution times due to difference in the void volume of the connecting path.

The ${ }^{1} \mathrm{H}$ NMR spectrum of the PMMA $\left(\bar{M}_{n}=12600\right)$ stored as a single file for the

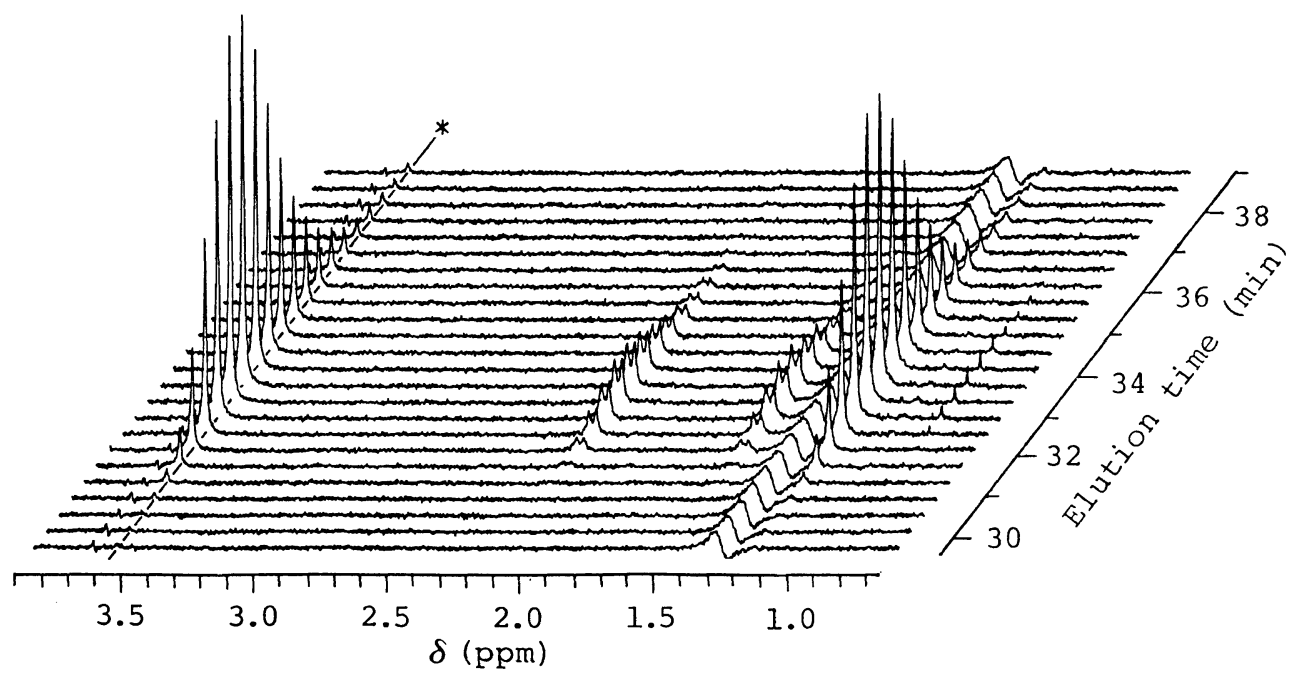

Figure 2. On-line GPC/NMR data of isotactic PMMA $\left(\bar{M}_{n}=12600\right)$. Cross section at $3.60 \mathrm{ppm}(*)$ where the methoxy proton resonates gives the ${ }^{1} \mathrm{H}$ NMR-detected GPC curve (see Figure 3 ).

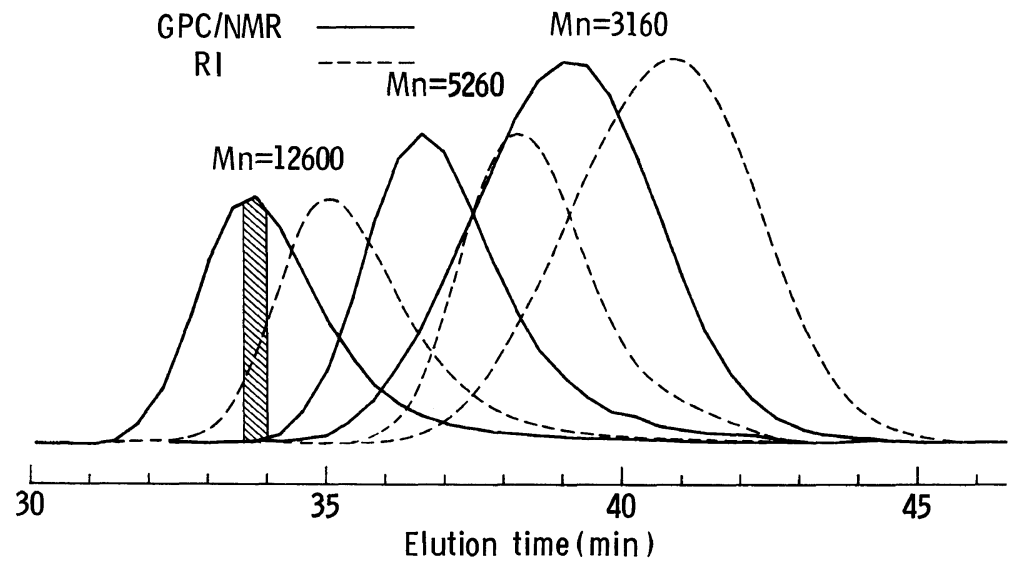

Figure 3. The ${ }^{1} \mathrm{H}$ NMR-detected GPC curves of the isotactic PMMAs with $\bar{M}_{n}$ s of 12600,5260 and 3160 . These curves were obtained by plotting the intensity of the methoxy proton signal $(3.60 \mathrm{ppm})$ against elution time. The RI-detected GPC curves are also shown. 


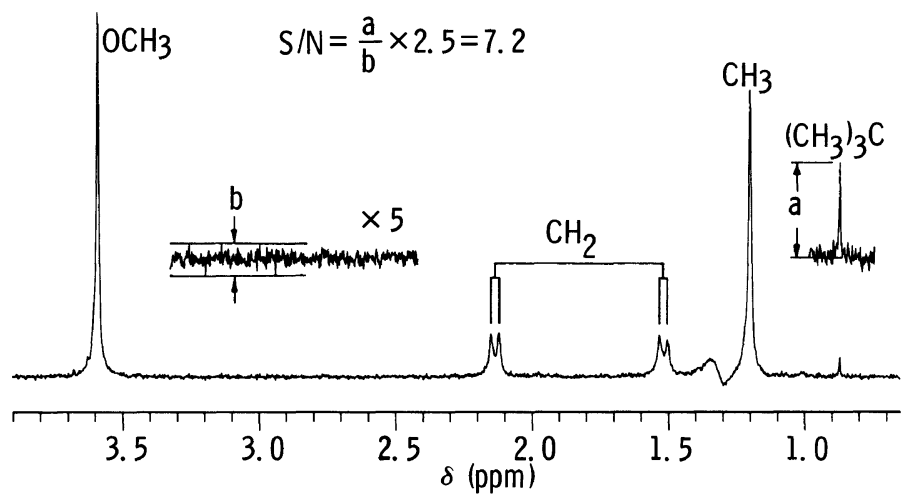

Figure 4. The ${ }^{1} \mathrm{H}$ NMR spectrum of the isotactic PMMA $\left(\bar{M}_{n}=12600\right)$ stored as a single file at the elution time from 33.6 to $34.0 \mathrm{~min}\left(45^{\circ}\right.$ pulse, 8 scans, 8192 data points covering $4500 \mathrm{~Hz}$, line-broadening factor of $0.55 \mathrm{~Hz}$ ). $\bar{M}_{n}$ of the PMMA detected in this file was calculated to be 11800 from the equation:

$$
\bar{M}_{n}=\mathrm{MW}(\text { monomer-unit }) \times \mathrm{DP}+\mathrm{MW} \text { (end-groups), }
$$

where $\mathrm{DP}=\left[I\left(\mathrm{OCH}_{3}\right) / 3\right] /\left[I\left(t-\mathrm{C}_{4} \mathrm{H}_{9}\right) / 9\right]=117$, MW (monomer-unit) $=\mathrm{C}_{5} \mathrm{H}_{8} \mathrm{O}_{2}=100, \mathrm{MW}$ (end-groups) $=$ $\mathrm{C}_{4} \mathrm{H}_{9}+\mathrm{H}=58$.

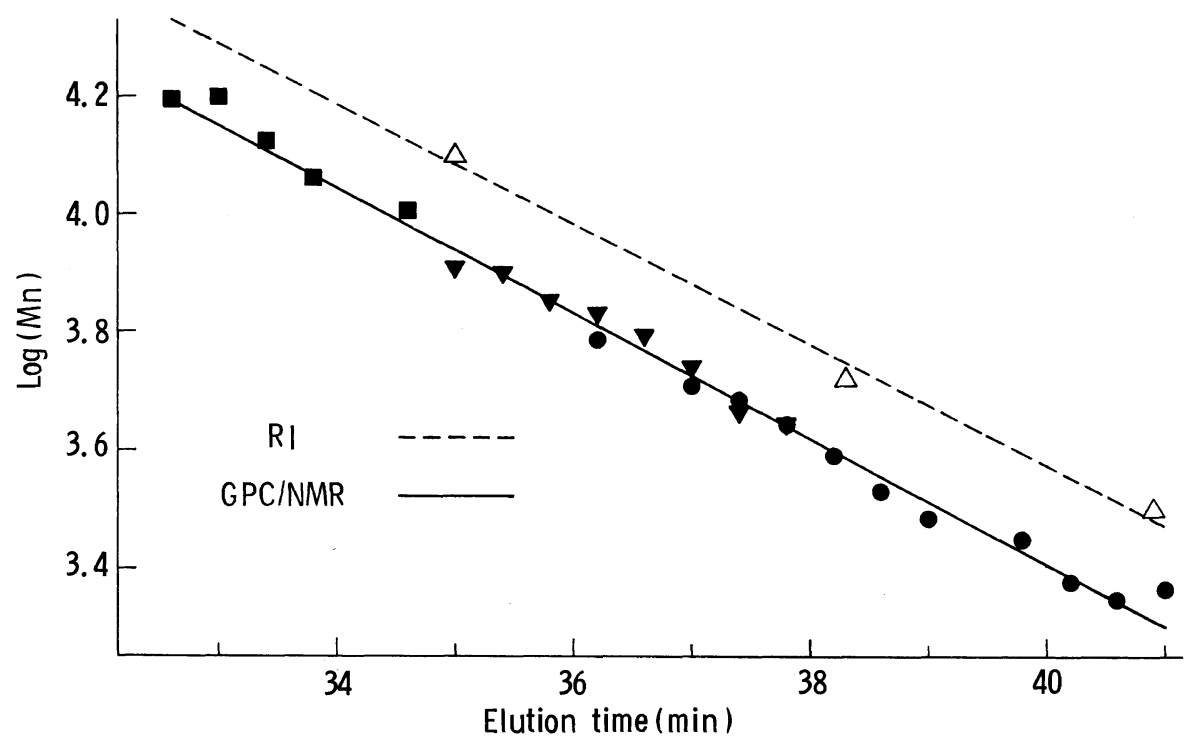

Figure 5. Plots of $\log \left(\bar{M}_{n}\right)$ of isotactic PMMAs determined from the intensity ratio for the ${ }^{1} \mathrm{H}$ NMR signal of $\mathrm{CH}_{3} \mathrm{O}$ - to $t-\mathrm{C}_{4} \mathrm{H}_{9}$ - against elution time; $\bar{M}_{n}=12600(\boldsymbol{\nabla}), 5260(\boldsymbol{\nabla}), 3160(\boldsymbol{O})$. The calibration curve made by plotting the $\log \left(\bar{M}_{n}\right)$ for the isotactic PMMAs $\left(\bar{M}_{n}=12600,5260,3160\right)$ against peak-maximum elution time using RI-detection is also shown ( $\triangle$ and broken line).

elution time from 33.6 to $34.0 \mathrm{~min}$ ( $c f$. Figure 3 ) is shown in Figure 4. The signal to noise ratio $(\mathrm{S} / \mathrm{N})$ for the $t-\mathrm{C}_{4} \mathrm{H}_{9}$ - end group is 7.2. The $\bar{M}_{n}$ of the PMMA detected in this file was calculated to be 11800 from the intensities of the signals due to the $\mathrm{CH}_{3} \mathrm{O}$ - and $t-\mathrm{C}_{4} \mathrm{H}_{9}$ groups. Similarly, spectra with good resolution and high $\mathrm{S} / \mathrm{N}$ were obtained for most of the files. The files which exhibit the $t-\mathrm{C}_{4} \mathrm{H}_{9}$ - signal with the $\mathrm{S} / \mathrm{N}$ less than 5 were added with 2 or 3 
contiguous files so that the ratio exceeded 5 . Thus the $\bar{M}_{n}$ of each fraction can be determined directly from the ${ }^{1} \mathrm{H}$ NMR spectrum. This is one of the great advantages of the online GPC/NMR system over dual detection systems such as UV-RI detectors or a variable wavelength $U V$-detector which requires calibration of the detected intensity of absorption due to end-groups and polymers for the real molecular weight.

The logarithm of the $\bar{M}_{n}$ determined from the ${ }^{1} \mathrm{H}$ NMR spectrum in each file is plotted against the elution time. The plots for all the three PMMA samples fall on a single straight line as shown in Figure 5 (solid line). The slope of the straight line is close to that of the calibration curve made by plotting $\log \left(\bar{M}_{n}\right)$ for the three PMMA samples $\left(\bar{M}_{n}=12600,5260\right.$, and 3160) against the peak-maximum elution time using an RI-detector (broken line in Figure 5). The calibration curve made by the GPC/RI method in this way is not completely correct because the $\bar{M}_{w} / \bar{M}_{n}$ values of 1.13 1.19 for the PMMA samples (Table I) are not small enough to regard their $\bar{M}_{n}$ s as the $\bar{M}_{n}$ at the peak-maximum elution time. Thus, the linear relation of $\log \left(\bar{M}_{n}\right)$ versus elution time obtained by this on-line GPC/NMR experiment should be the most accurate calibration curve for highly isotactic PMMA. The $\bar{M}_{w} / \bar{M}_{n}$ values calculated from the GPC/NMR method agreed well with those obtained from the normal GPC/RI method using standard polystyrenes as shown in Table I.

In our previous work ${ }^{4}$ we conducted similar experiments using the NMR flow cell without a tapered structure at both ends and found that the slopes of $\log \left(\bar{M}_{n}\right)$ versus elution time curve for the PMMA samples of different $\bar{M}_{n}$ s differed slightly from each other. This was considered due to broadening of the elution band by the turbulent flow in the inlet path of the flow cell. The present results clearly show that the tapered structures at both ends of the cell almost completely remove broadening.

The results mentioned here indicate the usefulness of on-line GPC/NMR for absolute calibration of molecular weight when polymer samples of well defined structure are available. It is noteworthy that a single sample with a broad molecular weight distribution is enough to make the calibration curve if the number of end groups per chain is well defined. On-line detection by ${ }^{1} \mathrm{H}$ NMR offers not only the absolute calibration curve but also information on the molecular weight dependency of some polymer-properties such as tacticity or copolymer composition at the same time. Thus, efforts for preparing the polymers of controlled structure should be encouraged for providing on-line GPC/NMR with suitable polymer samples.

\section{REFERENCES}

1. W. Kaye and A. J. Havlik, Appl. Optics, 12, 541 (1973).

2. H. A. Andreetta, I. H. Sorokin, and R. V. Figini, Makromol. Chem., Rapid Commun., 6, 419 (1985).

3. T. Q. Nguyen and H. H. Kausch, J. Chromatogr., 449, 63 (1988).

4. K. Hatada, K. Ute, Y. Okamoto, M. Imanari, and N. Fujii, Polym. Bull., 20, 317 (1988).

5. K. Hatada, K. Ute, T. Kitayama, M. Yamamoto, T. Nishimura, and M. Kashiyama, Polym. Bull., 21, 489 (1989).

6. K. Hatada, K. Ute, T. Nishimura, M. Imanari, and N. Fujii, Polym. Prepr. Jpn., 37, E431 (1988).

7. K. Ute, M. Kashiyama, K. Oka, K. Hatada, and O. Vogl, Makromol. Chem., Rapid Commun., 11, xxx.

8. K. Hatada, K. Ute, K. Tanaka, Y. Okamoto, and T. Kitayama, Polym. J., 18, 1037 (1986).

9. J. F. Haw, T. E. Glass, and H. C. Dorn, Anal. Chem., 53, 2327 (1981).

10. K. Albert and E. Bayer, Trends Alal. Chem., 7, 288 (1988). 